\title{
On the Measurement of Benefits in an Urban Context: Some General Equilibrium Issues
}

\author{
Paul N. Courant \\ Department of Economics and Institute of Public Policy Studies, \\ The University of Michigan, Ann Arbor, Michigan 48109
}

AND

DANiel L. Rubinfeld

National Bureau of Economic Research and Department of Economics and Institute of Public Policy Studies, The University of Michigan, Ann Arbor, Michigan 48109

Received May 14, 1976; revised November 22, 1976

The validity of using local market data to measure the benefits associated with policies adopted in an urban area is investigated. It is shown that the rest of the world is affected by taxing decisions undertaken in a single urban area, so that local data cannot perfectly measure the welfare effects of a policy change. Specifically, the fact that the willingness to pay for a tax increase is positive in the rest of the world suggests that cost-benefit analyses which do not account for the rest of the world may be biased.

\section{INTRODUCTION}

Numerous attempts have been made to utilize market data to measure the benefits associated with public policy changes in an urban area. The majority of these studies have attempted to determine the relationship between property values and certain policy-related variables, such as local taxes, expenditures, and environmental quality, in order to obtain an estimate of the willingness to pay for changes in these variables. ${ }^{1}$ Recent analyses of property value studies have been critical of them, pointing to the fact that a correct measure of the benefits associated with a change in publie policy must take into account the willingness to pay of all relevant economic actors in the urban area. ${ }^{2}$

${ }^{1}$ For reference to some examples of these property value studies, see Polinsky and Rubinfeld [2,3].

${ }^{2}$ See Polinsky and Rubinfeld [3] for a model in which the relationship between these economic factors and willingness to pay is discussed. 
Because these methodological discussions focus on the measurement of benefits within one urban area in a large system of urban areas, it is usually assumed that the price of capital is unaffected by any local change in public policy, so that capital owners have a zero willingness to pay for the policy change. Such an assumption can be quite misleading, however, because the assumption that the price of capital changes insignificantly (so that it may be assumed constant), does not allow one to conclude that it is reasonable to assume that the value of capital (price times quantity) in the system of urban areas has changed negligibly. In fact, it seems quite plausible that the willingness to pay for a local policy change on the part of all owners of capital may be quite large. If so, there may be a substantial bias involved if one analyzes local public policy decisions without accounting for the willingness to pay of economic actors outside the urban area which is directly affected by the public policy change.

To explore these issues, we utilize a model in which capital and land are inputs in the production of a homogeneous good in a system of urban areas. Land is fixed in each urban area, while capital is perfectly mobile among urban areas. The model is used to analyze the consequences of a newly imposed tax on all capital utilized in one urban area. We find that while the price of capital may change only slightly, the tax increase will, in general, result in a large decline in the value of capital in the system of urban areas, and consequently, a large negative willingness to pay of capital owners in the "rest of the world." However, we also find that the willingness to pay of capital owners is to a large extent counterbalanced by the positive willingness to pay of land owners in the rest of the world, so that the total willingness to pay for the policy change outside of the taxed urban area is a small fraction of the willingness to pay of capital owners. The fact that this total willingness to pay in the rest of the world is positive suggests (in the context of the model) that cost benefit analyses which account only for the urban area impacted by a policy change may be biased. Finally, we compare the magnitude of willingness to pay measured in the urban area in which policy changes occur and willingness to pay in the rest of the world. We find that the allocative bias associated with the measurement of benefits within the impacted urban area will not necessarily be small. In one extreme case, onc-third of the welfare effects of the tax take place outside of the taxed urban area.

In Section II the model of production in a system of urban areas is formally presented. In Section III willingness to pay is defined in the context of this model, and the questions raised above are reformulated in terms of the model. The model is then used to analyze and at least partially answer the questions. Section IV contains some conclusions as well as suggestions for extension of our analysis. 


\section{THE MODEL}

The following model is admittedly unrealistic, but is structured so as to capture those features which are crucial to the cost-benefit issues raised in Section I. Consider a set of $N$ urban areas, ${ }^{3}$ each producing identical output by means of the production function

$$
q_{i}=F(K / N, L / N),
$$

where $q_{i}$ is the output of the $i$ th urban area, $K$ is the capital (or perfectly mobile) input, and $L$ is the land (or immobile) input, and $F$ is homogeneous of degree 1 . We assume that there is a fixed supply of capital $K$ in the system, and a fixed supply of land, $L / N$ in each urban area. Since land is fixed we will suppress the land input and represent the production function as $f(K / N)$. We assume further that owners of capital and land have identical utility functions, with utility monotonically increasing in output. In this situation, utility maximization is equivalent to profit maximization, as both capital owners and landlords seek to maximize their claims on output. If it is assumed that factor markets are competitive, we may write the first-order condition for profit maximization with respect to the capital input of the ith urban area as follows':

$$
f_{K}=s \text {, }
$$

where $s$ is the rental price of capital and the subscript denotes the partial derivative with respect to capital.

The assumption of competitive behavior in factor and output markets requires that the portion of output not claimed by capital owners be received by the landlords. Given our homogeneity assumption, this implies that:

$$
r=r_{i}=\left[q_{i}-s(K / N)\right] /(L / N),
$$

where $r$ is the annual rental price of land. Note that $r$ and $s$ are defined as claims on physical output per unit of input employed. This formulation obviates the need for explicit consideration of changes in output price in the following discussion.

Now consider the impact of a newly imposed tax at rate $t$ on the use of capital in urban area $1 .^{5}$ To simplify the exposition which follows, two

${ }^{3}$ Each urban area may also be considered to be a single firm operating in a competitive market.

${ }^{4}$ We are implicitly assuming that $F_{K}, F_{L}>0$, and $F_{K K}, F_{L L}<0$.

${ }^{5}$ We have chosen to consider a newly imposed tax rather than an increment to an existing tax to simplify the analysis which follows. Our model yields substantively the same results as a model which analyzes the impact of a marginal (rather than a discrete) increase in preexisting tax. (For an alternative discussion of the relationship between marginal and nonmarginal changes, see Kraus [1]). However, in the special case of a marginal change in the tax rate from a point of global optimality (no tax), there is no deadweight Ioss, and the willingness to pay for the tax change is zero in all urban areas, 
conventions are used; first, we associate upper case letters with the aggregate of the remaining $N-1$ areas, and second, we associate variables with primes with the after-tax equilibrium. After the imposition of the tax, the first-order condition for the first urban area differs from the conditions for the remaining urban areas. In particular, for the first urban area:

$$
f_{K}^{\prime}=s^{\prime}(1+t)
$$

The tax on capital will lead to an outflow of capital, $\Delta K$, from the first urban area, which in our model will be utilized in equal proportions by the remaining $N-1$ urban areas. Thus, the new output of the first urban area is:

$$
q_{1}^{\prime}=q^{\prime}=f(K / N-\Delta K) .
$$

Of this output $q^{\prime}$, we assume that the revenue $t s^{\prime}(K / N-\Delta K)$ is received by the "government" whose only role is to select future public projects which can be justified on cost-benefit grounds. In order for any taxexpenditure project to be so justified, the revenue must provide sufficient welfare to compensate capital and land owners for the excess burden introduced by the tax. In addition, the annual rental on land is computed (using the homogeneity and competitive assumptions) as a residual such that:

$$
r_{1}^{\prime}=\left[q^{\prime}-s^{\prime}(1+t)(K / N-\Delta K)\right] /(L / N) .
$$

Finally, the output of the remaining $N-1$ urban areas ${ }^{6}$ is:

$$
Q^{\prime}=(N-1) f[K / N+\Delta K /(N-1)] .
$$

We shall also find it useful to take into account (as a result of the firstdegree homogeneity assumption) that all nontaxed urban areas will earn zero profits before and after the tax change. Specifically,

and

$$
Q=s(N-1)(K / N)+r(N-1)(L / N)
$$

$$
Q^{\prime}=s^{\prime}(N-1)[K / N+\Delta K /(N-1)]+r^{\prime}(N-1)(L / N) .
$$

\section{MEASURING WILLINGNESS TO PAY}

Each economic actor's willingness to pay is defined as the maximum amount of output per year which could be taken after the imposition of the tax in the first urban area and leave the individual no worse off than before. For owners of land willingness to pay is simply the aggregate change in output received as land rentals, while for the owners of capital, it is the aggregate change in output received as capital rentals,

'The original output was $Q=(N-1) f(K / N)$. 
TABLE 1

Willingness to Pay Accounts

\begin{tabular}{|c|c|}
\hline \multicolumn{2}{|l|}{ Taxed urban area } \\
\hline Capital owners & $w_{K}=\left(s^{\prime}-s\right)(K / N)$ \\
\hline Land owners & $w_{L}=q^{\prime}-q-\left(s^{\prime}-s\right)(K / N)+s^{\prime} \Delta K-t s^{\prime}(K / N-\Delta K)$ \\
\hline Government & $w_{G}=t s^{\prime}(K / N-\Delta K)$ \\
\hline Total & $w=w_{K}+w_{L}+w_{G}=q^{\prime}-q+s^{\prime} \Delta K$ \\
\hline
\end{tabular}

Rest of the world

$$
\begin{array}{ll}
\text { Capital owners } & W_{K}=\left(s^{\prime}-s\right)(K / N)(N-1) \\
\text { Land owners } & W_{L}=\left(r^{\prime}-r\right)(L / N)(N-1) \\
\text { Total } & W=W_{K}+W_{L}=Q^{\prime}-Q-s^{\prime} \Delta K
\end{array}
$$

Using the model structure presented in Section II, the willingness to pay of the relevant economic actors can be expressed analytically as shown in Table 1 . We continue with our notational convention by using $w$ to represent willingness to pay in the taxed area, and $W$ to represent willingness to pay in the rest of the world.

Equations (3.1), (3.5), and (3.6) in Table 1 follow directly from the definition of willingness to pay given above. For example, Eq. (3.1) measures the change in the annual rental value of the assets held by owners of capital in the taxed urban area. Note that the owners of capital in the rest of the world are affected only by the change in the value of the stocks that they hold prior to the imposition of the tax. The outflow of capital to the rest of the world as a consequence of the tax does not create capital gains (or losses), since capital users must pay a competitive price $\left(s^{\prime}\right)$ for any capital employed. Analogously, capital owners in the taxed area do not obtain capital gains or losses because they receive the world competitive price $s^{\prime}$ for use of their capital.

Equations (3.2), (3.4), and (3.7) follow from the first-order conditions of profit maximization and from the assumption that production is homogeneous of degree one. For example, to obtain Eq. (3.7), we add Eqs. (3.5) and (3.6) to obtain :

$$
W=((N-1) / N)\left[\left(s^{\prime} K+r^{\prime} L\right)-(s K+r L)\right] .
$$

But, rewriting Eqs. (2.8) and (2.9) we get

$$
((N-1) / N)(s K+r L)=Q
$$

and

$$
[(N-1) / N]\left(s^{\prime} K+r^{\prime} L\right)+s^{\prime} \Delta K=Q^{\prime}
$$

Substituting (3.9) and (3.10) into (3.8) yields (3.7) directly. 
Equation (3.2) equates the willingness to pay of land owners to the difference between the total willingness to pay in the urban area (3.4) and the willingness to pay of capital owners (3.1) and the government (3.3). This result follows directly from our assumption that land owners receive the residual gains and losses associated with the tax change.

The willingness to pay results are intuitively appealing. Equation (3.7), for example, states that annual willingness to pay in the rest of the world is equal to the increase in output due to the capital inflow, minus the annual rental value of the new capital. If this last term were not subtracted, double counting would be involved, since the new capital had to be rented at the competitive world rental price, and did not provide a capital gain to the capital owners in the rest of the world. Similarly, Eq. (3.4) states that annual willingness to pay in the taxed area is the loss of output plus the annual rental value of the capital outflow. The value of the capital outflow measures the portion of the capital loss which capital owners in the urban area are able to recoup by renting their capital at the world price.

\section{Analysis of Cost-Benefit Issues}

The equations listed in the willingness to pay accounts provide the basis for an analysis of the cost-benefit issues described in the introduction to the paper. Specifically, we wish to show that:

(1) The change in the annual rental value of capital in the rest of the world may not be small.

(2) Willingness to pay of the rest of the world is small relative to the willingness to pay of capital owners in the rest of the world.

(3) Willingness to pay in the rest of the world is positive, implying that a cost-benefit analysis associated with the imposition of a tax in one urban area is always biased so as to understate the true benefits to society of the project.

(4) Willingness to pay in the rest of the world may be large in relation to willingness to pay in the urban area. Only when willingness to pay in the rest of the world is relatively small is it a good approximation to assume that all of the change in economic welfare will occur in the taxed urban area.

Without further specifying the properties of the production functions involved, we are not able to obtain a simple comparison of the relevant magnitudes in the willingness to pay accounts. To permit more precise calculations of willingness to pay, therefore, we assume that the capital inflow to one urban area is sufficiently small so that $f_{K K}$ is constant (i.e., $f_{K K K}=0$ ) over the interval $K / N$ to $K / N+\Delta K /(N-1){ }^{7}$

${ }^{7}$ This implies that the marginal product of capital diminishes at a constant rate, and is equivalent to assuming that $\Delta K /(N-1)$ is closely approximated by the differential $d K$. 
To analyze the first assertion we utilize Eys. (2.2) and (2.7) to rewrits Eq. (3.5) as follows:

$$
W_{K}=K(N-1) / N\left\{f_{K}[K / N+\Delta K /(N-1)]-f_{K}(K / N)\right\}
$$

But, by our assumption, we may write

$$
f_{K}[K / N+\Delta K /(N-1)]=f_{K}(K / N)+f_{K K} \Delta K /(N-1) .
$$

Substituting into (3.11) we get:

$$
W_{K}=K f_{K K} \Delta K / N .
$$

In general, this term will be negative, since $f_{K K}$ is negative. More importantly, however, the value of $W_{K}$ may be quite large, since there is no reason to expect $K \Delta K$ to be small in a system with a finite number of urban areas. Thus, we can conclude that the willingness to pay of capital owners in the rest of the world will be negative, but not necessarily small.

To prove the second assertion, we utilize the following cxpression for the increased output in the rest of the world:

$$
Q^{\prime}-Q=(N-1) \int_{K / N}^{K / N+\Delta K /(N-1)} f_{K}(k) d k
$$

Substituting into Eq. (3.7) and utilizing Eq. (3.12), we may write

$$
\begin{array}{r}
W=(N-1) \int_{K / N}^{K / N+\Delta K /(N-1)}\left[f_{K}(K / N)+\left(f_{K K}\right)(k-K / N)\right] d k \\
-\left[f_{K}(K / N)+\left(f_{K K}\right)(\Delta K) /(N-1)\right] \Delta K .
\end{array}
$$

Integrating and solving we get:

$$
W=-f_{K K}(\Delta K)^{2} / 2(N-1) .
$$

Then, dividing by $W_{K}$ in Eq. (3.13) and taking absolute values, we get:

$$
\left|W / W_{K}\right|=[\Delta K / 2 K][N /(N-1)] .
$$

The absolute value of $W / W_{K}$, the ratio of the capital outflow from the taxed area to twice the amount of capital in the world, is clearly small.

The third assertion can be seen directly by noting that $W$ is strictly positive in Eq. (3.16). To see this intuitively note that the change in output in the rest of the world is the result of an increase in capital and a decrease in the marginal product of capital, with the consequence that the price of capital falls from $s$ to $s^{\prime}$. On the other hand, the entire change in the capital stock is evaluated at the now world price $s^{\prime}$. Thus, the increased value of output will exceed the absolute value of the change 
in the capital stock by an amount equal to the area of a triangle with height $\left(s-s^{\prime}\right)$ and base $\Delta K .^{8}$

In considering the fourth assertion, it is no longer valid to use the approximation of a constant second derivative of output with respect to capital, sinee the capital outflow in the taxed area may be large relative to its total capital stock. However, we can obtain useful bounds for the ratio of willingness to pay in the taxed area, $w$, to willingness to pay in the rest of the world, $W$, by temporarily maintaining the assumption that $f_{K K}$ is constant, or equivalently that $f_{K K K}=0$. To obtain these bounds we rewrite Eq. (3.4) to obtain an equation analogous to Eq. $(3.15)$ :

$$
\begin{aligned}
& u=\int_{K / N}^{K / N-\Delta K}\left[f_{K}(K / N)+\left(f_{K K}\right)(k-K / N)\right] d l \\
&+ {\left[f_{K}(K / N)+\left(f_{K K}\right)(\Delta K) /(N-1)\right] \Delta K . }
\end{aligned}
$$

Integrating and solving, we get:

$$
w=\left[f_{K K}(\Delta K)^{2} / 2\right][(N+1) /(N-1)] .
$$

Then, dividing $w$ by $W$ in Eq. (3.16) and taking absolute values, we get:

$$
|w / W|=(N+1) .
$$

Thus, if $f_{K K K}=0$, the magnitude of willingness to pay in the taxed area is exactly $N+1$ times the magnitude of willingness to pay in the rest of the world. This estimate is useful because it provides a lower bound for the true ratio of $w$ to $W$ in the case where $f_{K K K}>0$. In this case the marginal product of capital increases at an increasing ratc as capital flows out of the taxed area. When compared to the case in which the marginal product increases at a constant rate (in $\mathrm{Eq}$. (3.18)), the lower bound result becomes clear.

An illustration of this is given in Table 2, which presents the values of key variables of the model for a Cobb-Douglas production function associated with different tax rates. The third partials of a Cobb-Douglas are, of course, positive, and it is readily seen that the ratio of $|w|$ to $|W|$ is greater than $N+1$ in all cases.

${ }^{8}$ The third assertion is not dependent upon the simplifying assumption necessary to prove the first two assertions. This result follows after some manipulation if we subtract $\mathrm{s}^{\prime} \Delta K$ from both sides of Eq. (3.14) to obtain

$$
Q^{\prime}-Q-s^{\prime} \Delta K=(N-1) \int_{K / N}^{K / N+\Delta K /(N-1)}\left\{f_{K}(k)-f_{K}[K / N+\Delta K /(N-1)]\right\} d k .
$$

This integral is always positive since the marginal product of capital is always declining over the range of integration. 
TABLE 2

Cobb-- I Houglas Example:

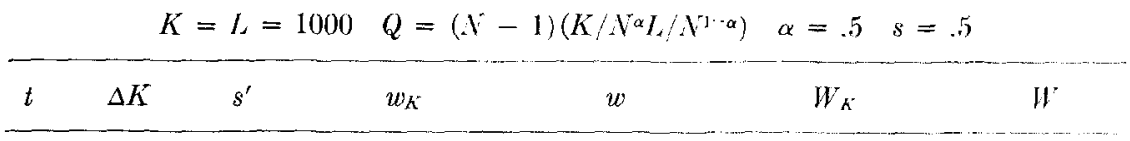

Case $1 ; N=100$

$\begin{array}{lllllll}0.01 & 0.19 & 0.4999 & -4.9 \times 10^{-4} & -4.9 \times 10^{-4} & -4.9 \times 10^{-2} & +4.9 \times 10^{-6} \\ 0.1 & 1.72 & 0.4996 & -4.3 \times 10^{-3} & -0.04 & -4.3 \times 10^{-1} & +3.7 \times 10^{-4} \\ 1.0 & 7.48 & 0.4981 & -1.9 \times 10^{-2} & -1.26 & -1.9 & +7.0 \times 10^{-3}\end{array}$

Case $2 ; N=10$

\begin{tabular}{ccccccc}
$t$ & $\Delta K$ & $s^{\prime}$ & $w_{K}$ & $w$ & $W_{K}$ & $W$ \\
0.01 & 1.78 & 0.4995 & $-4.9 \times 10^{-2}$ & -0.005 & $-4.4 \times 10^{-1}$ & $+4.3 \times 10^{--4}$ \\
0.1 & 15.90 & 0.4956 & $-4.4 \times 10^{-1}$ & -0.41 & -3.9 & $+3.5 \times 10^{-2}$ \\
1.0 & 72.97 & 0.4809 & -1.9 & -12.92 & -17.2 & $+6.8 \times 10^{-1}$ \\
\hline
\end{tabular}

There is nothing in neoclassical production theory, however, which assures that $f_{K K K}$ is everywhere positive. For example, it can be shown that a CES production function with an elasticity of substitution less than 0.5 will have negative third partials at some factor ratios. By the same logic that makes $N+1$ a lower bound of the ratio of $|w|$ to $|W|$ where $f_{K K K}$ is nonnegative over the relevant range, it is clear that $N+1$ is an upper bound for that ratio where $f_{K K K}$ is nonpositive.

The situation in which the ratio of $|w|$ to $|W|$ is smallest occurs when the marginal product of capital rises negligibly in the taxed urban area as capital flows out, although it falls nonnegligibly in the rest of the world. To approximate this situation, we assume that the marginal product of capital remains constant in the taxed area. Then Eq. (3.18) is simply

$$
\begin{aligned}
w=\int_{K / N}^{K / N-\Delta K} f_{K}(K / N) d k & \\
& +\left[f_{K}(K / N)+\left(f_{K K}\right)(\Delta K) /(N-1)\right] \Delta K .
\end{aligned}
$$

Equation (3.21) simplifics to:

$$
w=\frac{f_{K K}(\Delta K)^{2}}{N-1} .
$$

The absolute value of this last expression is twice that of $W$, willingness to pay in the rest of the world. The implications of this may be quite serious. In the rather extreme case of Eqs. (3.21) and (3.22), fully onethird of the welfare effects of the tax take place outside the taxing jurisdiction-regardless of the number of urban areas in the system. 


\section{CONCLUSIONS}

To the extent that the model used in this paper is applicable to "real world" cost-benefit problems, the results derived in Section III establish the following:

(1) When the measurement of benefits is restricted to the immediate urban area, the results of the cost-benefit analysis will, in general, be biased, in that a project which taxes a mobile factor in one urban area will (due to the outflow of that factor) lead to positive benefits in the rest of the world. However, the magnitude of that bias is likely to be small.

(2) A project which is financed through a tax on a mobile factor will have important distributive implications in the rest of the world. Holders of the taxed factor in the nontaxed areas will experience capital losses several orders of magnitude larger than the net welfare gain experienced in those areas. Furthermore, holders of other factors will receive capital gains slightly larger in magnitude than the eapital losses experienced by holders of the taxed factor. Thus, although the allocative bias derived from a project undertaken in one urban area may be small in the rest of the world, there can be a significant change in the functional income distribution of an entire system of urban areas due to the taxing policy of one urban area. ${ }^{9}$

(3) While the allocative bias in cost-benefit analysis will always be small in magnitude, it will not necessarily be small relative to excess burden in the taxing jurisdiction itself. Indeed, if the production function has a negative third partial with respect to capital, as much as one-third of the total welfare effect may occur outside of the taxing jurisdiction.

It might seem surprising to some readers that the willingness to pay in the rest of the world associated with the tax increase is not identically zero, since the tax impacts directly on the first urban area. For a nonmarginal change in the tax rate, however, it is necessary to examine the impact on the entire capital market to correctly calculate willingness to pay. This follows because the tax in the first urban area results in an outflow of capital to the rest of the world, with only the last unit of capital being paid its marginal product. Since all of the inframarginal units of capital flowing into the rest of the world have been paid less than their marginal product, there is a net positive willingness to pay in the rest of the world. Of course, the world willingness to pay is simply the net

\footnotetext{
${ }^{9}$ Recalling that the model used here is equivalent to a model of a system of firms in a competitive industry, we conclude that the standard assumption that factor prices may be treated as roughly constant in response to a change in behavior in one firm is appropriate. However, the product of price times quantity (i.e., total factor returns) is not approximated by a constant. This is verified in Table 2 .
} 
loss in real output resulting from the tax. Thus, our concern lies with the problem of the distribution of benefits among urban areas, a perspective which is somewhat different from that of most cost-benefit analyses.

The central purpose of this paper has been to investigate the validity of using local market data to measure the benefits associated with policies adopted in a given urban area. While a more claborate model, including more than one product, price changes, and a mobile labor force, can be expected to yield further insights into this question, the model presented here does provide a beginning. In brief, the rest of the world is affected by taxing decisions undertaken in a single urban area. Thus local data can never perfectly measure the welfare effects of a policy change. However, the magnitude of the welfare change in the rest of the world is likely to be quite small, as a result of offsetting changes in factor returns that may be quite large. Thus, local policies can have important implications for income distribution in a large system. Finally, in what may be a special case, but a special case that cannot be ruled out on theoretical grounds, the rest of the world may have good reason to be concerned with the tax policy in Peoria.

\section{ACKNOWLEDGMENTS}

The authors wish to thank Theodore C. Bergstrom, Alan V. Deardorff, Herbert Mohring, Wallace Oates, A. Mitchell Polinsky, Richard C. Porter, and Sidney G. Winter, Jr., for their helpful comments and suggestions.

\section{REFERENCES}

1. M. Kraus, Differential tax incidence: Large versus small tax changes, J. Political Econ. 80 (January/February, 1972).

2. A. M. Polinsky and D. L. Rubinfeld, The long-run effects of a residential property tax and local public services, J. Urban Econ. 5, 241-262 (1978).

3. A. M. Polinsky and D. L. Rubinfeld, Property values and the benefits of environmental improvements: Theory and measurement, in "Public Policy and the Quality of Life in Cities" (Wingo and Evans, Eds.), Resources for the Future for Johns Hopkins Press (1978). 